\title{
Produção de saber e poder sobre a sexualidade: análise crítica dos relatórios Kinsey, Master \& Jonhson e Hite
}

\author{
Sexualidades, estatísticas e \\ normalidades: a persona \\ numerabilis nos relatórios Kinsey, \\ Master \& Jonhson e Hite.
}

SENA, Tito.

Prefácio de Mara Lago e Miriam Grossi.

Florianópolis: Ed. Mulheres, 2013. 288 p.

Tito Sena, em seu livro Sexualidades, estatísticas e normalidades: a persona numerabilis nos relatórios Kinsey, Master \& Jonhson e Hite, revisitará os mais conhecidos relatórios sobre a sexualidade: Kinsey, Master \& Johnson e Hite, analisando-os à luz dos contextos históricos nos quais nasceram. O texto é fruto de sua tese de doutoramento no Programa Interdisciplinar de Ciências Humanas da UFSC, construída sob a orientação das doutoras Mara Coelho de Souza Lago e Míriam Pillar Grossi.

O interesse pelas questões da sexualidade vinha acompanhando o autor desde seus cursos de especialização e de mestrado, sendo tais questões objeto tanto de sua monografia quanto de sua dissertação. Nesse percurso, ao depararse com inúmeras citações dos referidos relatórios, o autor decide debruçar-se sobre eles. $O$ que o move é a busca por compreender como o produto daquelas pesquisas sobre a sexualidade humana confere o status de verdade sobre as sexualidades individuais.

Em sua obra, o autor denuncia o poder da ciência de estabelecer, via estratégias estatísticas, padrões normativos e de saúde sexual, e, com olhar crítico, cria a expressão persona numerabilis, apontando que esses relatórios falam de números e práticas sexuais, mas não apagam o fato de que a sexualidade é sempre de um por um. Além disso, discute os efeitos que esses relatórios produzem ao criarem normalidades, padrões e tratamento, os quais passam a mediar as relações das pessoas com suas sexualidades.

Aponta também os efeitos positivos dos relatórios, como a desmistificação das práticas sexuais, que geraram efeitos de maior liberdade e naturalidade frente à sexualidade na cultura. Para muitas pessoas, encontrar nos relatórios práticas sexuais antes tidas como abjetas possibilitou a conciliação com suas próprias sexualidades.

Dentre esses efeitos, assinala o impacto produzido na mídia, levando o discurso da sexualidade para o cotidiano, retirando-o do espaço privado e médico. Os relatórios bateram recordes de vendagem e resultaram em milhares de artigos, trabalhos e novas pesquisas. Tendo sido produzidos nos Estados Unidos, um país que emergiu economicamente após a Segunda Grande Guerra e que acolheu grandes intelectuais oriundos da Europa, tais relatórios inseriram-se no grande peso simbólico que a cultura americana imprimiu em diversos países, inclusive no Brasil.

O livro está dividido em seis capítulos. No primeiro, o autor discorre sobre como realizou sua análise. Inicia discutindo a interdisciplinaridade e assinala que o que caracteriza uma pesquisa interdisciplinar é o atravessamento do tema por olhares de diversas disciplinas, resguardando as fronteiras de cada uma, mas estabelecendo um diálogo entre elas, numa relação de reciprocidade. Caracteriza seu processo como um estudo histórico e documental, ressaltando a importância da contextualização histórica das fontes. Encontra em Foucault as ferramentas para sua análise: a arqueologia - que lê os discursos a partir de suas condições de emergência histórica e possibilidades de existência enunciativa - e a genealogia, enquanto estratégia de investigação dos poderes construídos a partir desses saberes.

No segundo capítulo, discute a questão da verdade a partir de Nietzsche, apontando que, apesar de não ser absoluta, deve ser buscada, sem que se perca de vista que é convencional e arbitrária. Com Foucault, afirma que há duas vias para a produção da verdade sobre o sexo: a ars erótica, que visa extrair a verdade do prazer; e a ciência sexualis, que visa saberes científicos sobre o sexo. Desta, resultam a normatização, enquanto forma de saber, e a normalização, enquanto forma de poder; ou seja, fixações enquadradoras dos 
corpos, que patologizam o que desvia da norma. E demonstra que Freud escapa dessas duas vias, afirmando a "[...]existência de um continuum de práticas sexuais difíceis de serem rotuladas, efetivamente, como desviantes ou anormais" (p. 86).

Ainda nesse capítulo, aborda o feminismo e os estudos de gênero, que concebem gênero como constructos históricos e ficcionais, apoiados em diferenças biológicas tidas como naturais, e afirma: "Não temos o corpo biológico, natural, da criança, do idoso, do louco, do preso, do homossexual: temos o corpo-história-criança, corpo-história-idoso, corpo-história-louco, corpohistória-homossexual."(p. 99). Sena apropria-se aqui da crítica feminista à naturalização das identidades e ressalta que os estudos de gênero pós-modernos são desconstrutuvistas, não visam ao estabelecimento de novas verdades, mas questionam as crenças relacionadas à verdade, o que os aproxima de Foucault.

O terceiro capítulo apresenta um mapa discursivo e extradiscursivo, pontuando, a partir de várias perspectivas, as condições históricas nas quais os relatórios foram realizados. Para tanto, aborda a tecnologia, o cinema, a psicometria, as proibições sexuais, as políticas sanitárias, as mulheres, a demografia, a psiquiatria, a estatística e acontecimentos das décadas de 50, 60 e 70 do século XX. Nesse mapeamento correlacional de discursos, a categoria gênero aparece sempre em destaque. Sena ressalta: a consolidação dos métodos científicos, com seus efeitos de quantificação, que redundaram na formalização de todo o conhecimento em princípios lógicos; a fixação da mulher ao lar no pós-guerra, mas já como novos modos de relação conjugal estabelecidos; o cinema como produtor de estilos de vida; e os movimentos eugênicos, que buscavam melhorar as qualidades físicas e mentais de gerações futuras, originando saberes como a psicometria. Segundo o autor, é nesse ambiente que surge a Fundação Rockefeller, a qual, inicialmente, financia a pesquisa de Kinsey. Além disso, correlaciona a retomada do poder pelos democratas nos EUA como viabilizadora da publicação dos relatórios.

No quarto capítulo, Sena aborda os relatórios Kinsey. Apresenta os principais resultados encontrados nas pesquisas realizadas com mulheres e homens brancos americanos. Diz que o principal objetivo de Kinsey teria sido demonstrar que aquilo que usualmente era considerado anormal, no que diz respeito à sexualidade humana, não era tão anormal de fato.
Afirma que esse pesquisador era crítico audaz das legislações norte-americanas pautadas em códigos religiosos, descompassados em relação às mudanças de comportamento sexual do pós-guerra. Expõe diversas análises dos relatórios, algumas críticas, outras que reconhecem seus efeitos nas legislações e nas mudanças culturais. $O$ aspecto final apontado é a produção multiplicadora de discursos sobre a vida sexual e seus estudos.

No quinto capítulo, aborda os relatórios Masters \& Johnson, resultado das pesquisas do ginecologista William Masters e da psicóloga Virgínia Johnson. Esses relatórios, segundo Sena, visavam a um enfoque de natureza fisiológica, em contrapartida ao caráter sociológico do relatório Kinsley, e resultaram em propostas terapêuticas para o tratamento das disfunções sexuais. A pesquisa centrava-se na fisiologia e anatomia das respostas sexuais masculinas e femininas, com ênfase na pesquisa das respostas femininas.

Para o autor, o sofisticado aparato de equipamentos tornava a investigação biológica e micrométrica. Refere críticas referentes à pouca espontaneidade e artificialidade das relações sexuais programadas para a pesquisa, e destaca que, para Master \& Johnson, os problemas sexuais seriam tributários da unidade conjugal, e não individuais. Sena afirma, ainda, que subjazia ao estudo uma defesa do casamento monogâmico, e que a amostra consistia de americanos brancos, de camadas privilegiadas, levando a deduções questionáveis, no que concerne às camadas mais desfavorecidas da população. Menciona autores que consideram que esses relatórios reforçaram a concepção de disfunção sexual e estimularam o tratamento medicamentoso. Ressalta, por outro lado, que esses relatórios foram muito bem acolhidos pelas feministas e teriam contribuído muito para as suas causas e direitos, uma vez que expunham posições verdadeiramente progressistas no que diz respeito à sexualidade das mulheres.

No último capítulo, o livro aborda os relatórios Hite, fortemente influenciados pela segunda onda do feminismo nas décadas de 1960 e 1970 . Esses relatórios foram realizados a partir de questionários abertos e procuraram abranger grupos raciais e étnicos, pesquisados acima de 65 anos e "inválidos". Sena refere que uma das características desses relatórios foi o fato de apresentarem narrativas e citações para corroborar os resultados. Ainda segundo o autor, Hite visava investigar dois grandes mitos sobre a sexualidade feminina: que as mulheres teriam menor interesse por sexo e que a natureza feminina implicaria uma maior demora 
para gozar. Ainda de acordo com Sena, Hite critica o endeusamento do coito e do orgasmo, e afirma que as conclusões de Kinsey contribuíram para patologizar a sexualidade. Essa autora proporia uma (in)definição da sexualidade, de modo que cada um pudesse descobrir seus potenciais corpóreos para o prazer. Com relação aos estudos produzidos a partir dos relatórios, Sena cita Neckel, que comenta a influência da produção discursiva americana sobre a sociedade brasileira, uma vez que resultados dos relatórios foram disseminados por veículos de comunicação, como revistas dirigidas a homens e mulheres, resultando em possíveis enquadramentos descontextualizados. Sena conclui afirmando, orientado a partir de Foucault, que o reconhecimento dessa pesquisa se deu no âmbito do critério histórico, e não do critério de cientificidade.

O autor finaliza colocando que seus objetivos eram problematizar as verdades apresentadas nos relatórios, apontar como as instituições se apropriam de discursos sobre a sexualidade, e demonstra que isso redunda no surgimento da "persona numerabilis", a qual definirá a "persona normalis" e, em consequência, a "persona sexualis". Aponta o perigo que daí decorre: as sexualidades descritivas transformam-se em sexualidades prescritivas, criando sexualidades normais ou verdadeiras; e ressalta que "[...] pessoas não são números, pessoas não são dados de nenhuma espécie" (p. 250).

O livro Sexualidades, estatísticas e normalidades: a persona numeralibis nos relatórios Kinsey, Master \& Jonson e Hite, fruto da tese premiada pela Capes e que recebeu menção honrosa na área interdisciplinar em 2008, tornase uma leitura indispensável aos estudiosos da sexualidade e das questões de gênero, por possibilitar uma ampla visão, contextualizada e crítica, dos relatórios.

Jacqueline Virmond Vieira Universidade Federal de Santa Catarina 